\title{
Packing Density Improvement through Addition of Limestone Fines, Superfine Cement and Condensed Silica Fume
}

\author{
J. J. Chen ${ }^{*}$, A. K. H. Kwan'2, P. L. Ng2,3, L. G. Li ${ }^{4}$ \\ ${ }^{1}$ Foshan University, Foshan, China \\ ${ }^{2}$ The University of Hong Kong, Hong Kong, China \\ ${ }^{3}$ Vilnius Gediminas Technical University, Vilnius, Lithuania \\ ${ }^{4}$ Guangdong University of Technology, Guangzhou, China \\ Email: "chen.jiajian@yahoo.com.hk, khkwan@hku.hk, irdngpl@gmail.com, ligu123@msn.com
}

Received 31 March 2016; accepted 21 July 2016; published 25 July 2016

\begin{abstract}
Adoption of a low water/powder (W/P) ratio is the key to improve the strength and durability of concrete, which relies on a high packing density because fresh concrete requires excess water to offer flowability. To obtain a high packing density, powders with different particle sizes, including limestone fines (LSF), superfine cement (SFC), condensed silica fume (CSF), were added to the cement paste and the resulting packing densities were measured directly by a newly-developed wet packing test. Results demonstrated that addition of powders with a finer size would more significantly improve the packing density but the powders should be at least as fine as 1/4 of the OPC to effectively improve the packing density. Packing density and voids ratio relationship showed that a small increase in packing density can significantly decrease the voids ratio, which could allow the $\mathrm{W} / \mathrm{P}$ ratio to be reduced to improve the strength and durability of the concrete without compromising the flowability.
\end{abstract}

\section{Keywords}

Condensed Silica Fume, Limestone Fines, Packing Density, Superfine Cement, Voids Ratio

\section{Introduction}

To improve the strength and durability of concrete, an essential and important strategy is to lower the water/ powder (W/P) ratio [1]-[3]. However, it is impossible to unlimitedly lower the W/P ratio since certain amount of water is necessary to provide the concrete mix sufficient workability [4] to achieve proper compaction, to flow and spread to far-reaching corners and confined sections in the mould. Therefore, the key to the production of high-performance concrete (HPC) lies on minimization of the W/P ratio while keeping satisfactory workability and flowability.

${ }^{*}$ Corresponding author.

How to cite this paper: Chen, J.J., Kwan, A.K.H., Ng, L.P. and Li, L.G. (2016) Packing Density Improvement through Addition of Limestone Fines, Superfine Cement and Condensed Silica Fume. Journal of Materials Science and Chemical Engineering, 4, 29-36. http://dx.doi.org/10.4236/msce.2016.47005 
Research shows that it is the excess water (water in excess of that needed to fill the voids) that lubricates the cement paste and gives the concrete mix flowability because the water has to first fill up the voids in the bulk volume of the powder in a cement paste [5]. In view of the above situation, decrease of the voids ratio in the powder (the powder herein could be considered as particles finer than $75 \mu \mathrm{m}$ ) would allow a lower W/P ratio at the same flowability. Therefore, improvement in the packing density of powder to lower the voids ratio is essential in production of HPC.

The application of the packing density theory on the design of HPC has been hypothesized and investigated. Early in the 1960s, Powers [6] had pointed out that packing density of the powder materials played an important role in the performance of concrete. In 1985, tests by Huang and Feldman [7] and Feldman and Huang [8] had shown that addition of silica fume, an ultrafine supplementary cementitious material, could densify the cement paste matrix for performance improvement. In 1994, De Larrard and Sedran [9] used a packing model to maximize the packing density and successfully reduced the W/P ratio to 0.14 by weight and finally achieved a compressive strength as high as $236 \mathrm{MPa}$ for fluid mortar. In 1996, Sedran et al. [10] brought forward that the performance optimization of concrete was mainly a matter of improving the packing density of its granular skeleton. In 1997, Lange et al. [11] demonstrated that blending ordinary cement with finer materials could improve the packing density and that the dense packing of cement particles could result in high-strength mortar with low porosity, homogeneous microstructure, and great durability. In 2003, Jones et al. [12] found that the effectiveness of the fillers to reduce the voids content was dependent on whether a super plasticizer was present and that in general finer fillers were more effective especially when a super plasticizer was added to disperse the particles and reduce agglomeration.

To improve the packing density, addition of fine particles can fill the voids between cement grain particles. Like the packing of aggregate, it is generally believed that the addition of fillers smaller in size than cement would lead to packing density improvement. Albeit the effects of different fillers on concrete have been widely reported [13]-[22], their potential effects on packing density has been rarely researched and measured quantitatively. To fill this gap, the recently developed wet packing method was applied to measure the packing density of powder paste. A systematic experimental program was launched to study the effects of fine powders including limestone fines (LSF), superfine cement (SFC), and condensed silica fume (CSF) on the wet packing densities. It is noteworthy that the wet packing method is capable to incorporate the effects of super plasticizer and measure the packing density of very fine materials. This method overcomes a long-time difficulty namely the lack of a reliable method for measuring the packing density of powder materials.

\section{Wet Packing Method for Measurement of Packing Density}

Since the details of the wet packing method has been published elsewhere [23], an outline of the method is presented herein. Essentially, this method determines the packing density of the powder as the maximum solid concentration of pastes formed from the powder mixed with water at different W/P ratios. The solid concentration of the paste $\phi$ was determined from the following equation:

$$
\phi=\frac{M / V}{\rho_{w} u_{w}+\rho_{\alpha} R_{\alpha}+\rho_{\beta} R_{\beta}+\rho_{\gamma} R_{\gamma}}
$$

where $\rho_{w}$ is the density of water, $\rho_{\alpha}, \rho_{\beta}$ and $\rho_{\gamma}$ are the respective solid densities of powder materials $\alpha, \beta$ and $\gamma$ blended together, $u_{w}$ is the W/P ratio by volume and $R_{\alpha}, R_{\beta}$ and $R_{\gamma}$ are the volumetric ratios of $\alpha, \beta$ and $\gamma$ to the total powder.Six to eight samples of paste were formed of the powder with different water content and as a whole, the solid concentration would increase with the $\mathrm{W} / \mathrm{P}$ ratio at relatively low W/P ratios and then turn to decrease with the W/P ratio at relatively high W/P ratios as shown in Figure 1. This maximum solid concentration $\phi_{\max }$ would occur when the particles are tightly packed against each other whereby determining the packing density of the powder. Based on the packing density results, the voids ratio of the powder materials $e$ may be determined as

$$
e=\frac{1-\phi_{\max }}{\phi_{\max }}
$$

The effects of LSF, SFC, and CSF on the packing density were investigated by measuring the packing density of the powder paste prepared by blending the materials with cement, as detailed hereunder. 


\section{Materials}

The cement used was a grade 52.5N ordinary Portland cement (OPC). Three batches of OPC, which was denoted by batch 1, batch 2 and batch 3 , had been used for testing in this study due to different time when the tests were conducted. The LSF was a finely ground limestone normally used as an inert filler in concrete; the SFC was imported from Europe and it was a slag cement containing 80\% slag; the CSF was imported from Europe and it was normally used as a mineral admixture in concrete. The solid density and volumetric mean particle size of OPC, LSF, SFC and CSF are summarized in Table 1 while their particle size distributions were measured by laser particle size analyzer and plotted in Figure 2. It can be seen that the OPC has largest particle size amongst all the materials.

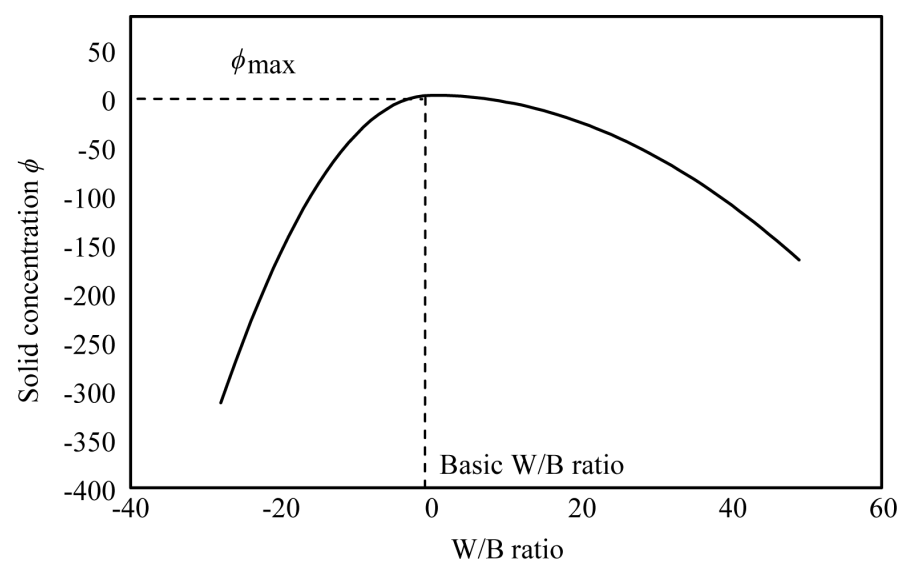

Figure 1. Solid concentration versus W/P ratio.

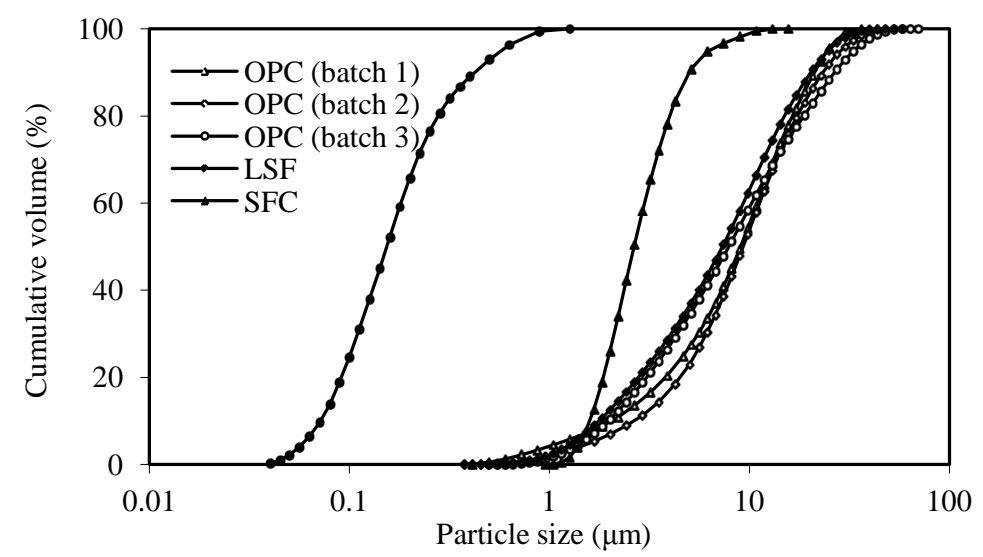

Figure 2. Particle size distributions.

Table 1. Solid density and volumetric mean particle size of the materials.

\begin{tabular}{ccc}
\hline Material & Solid density $\left(\mathrm{kg} / \mathrm{m}^{3}\right)$ & Volumetric mean particle size $(\mu \mathrm{m})$ \\
\hline OPC (batch 1) & 3112 & 12.4 \\
OPC (batch 2) & 3112 & 12.5 \\
OPC (batch 3) & 3112 & 11.4 \\
LSF & 2642 & 10.3 \\
SFC & 2940 & 3.1 \\
CSF & 2196 & 0.21 \\
\hline
\end{tabular}


The superplasticizer used in this study was a third generation polycarboxylate-based one. It was an aqueous solution with a solid mass content and a relative density of $20 \%$ and 1.03 , respectively. Basically, its molecular structure can be characterized by an active-monomer formed main chain attached with graft copolymers formed side chains. Compared to the earlier generation superplasticizers, this kind of superplasticizer is more effective as it can disperse fine particles by not only electrostatic repulsion and but also steric repulsion.

\section{Experimental Results}

In the following, the experimental results of packing densities by blending OPC with CSF, LSF, and SFC respectively are presented. The wet packing densities and voids ratio of powder paste produced from the OPC (batch 1) blended with different amounts of CSF ( $0 \%$ to $25 \%$ by volume of the whole cementitious materials) were measured and the results are shown in the Figure 3. These results clearly display the great benefit CSF brings to the packing density. With just 5\% OPC replaced by CSF, the packing density was already significantly increased by $4.1 \%$ from 0.654 to 0.681 ; while with $10 \%$ OPC replaced by CSF, the packing density continued to increased to 0.707 ; and with CSF replacement content increased to 25\%, the packing density kept on increasing to as high as 0.736 . The increase in packing density of powder due to addition of CSF was rather promising. It is because of the extreme fineness of CSF which could act as fillers to physically fill the voids between cement grains to increase the solid concentration. However, it should be noted that the rate of increase in the packing density with the CSF replacement content generally decreased at higher CSF content.

Figure 4 depicts the wet packing densities and voids ratio of powder paste produced from the OPC (batch 2) blended with different amounts of LSF ( 0 to $20 \%$ by mass of the cement). Results show that the addition of LSF could increase the packing density of powder, but the increase was only $2.0 \%$ from 0.640 to 0.653 even when the LSF content was increased up to as high as $20 \%$. Obviously, the packing density of the powder could only be marginally improved by addition of LSF to OPC. This is due to the fineness of both OPC and LSF are of the same order of magnitude. Therefore, the size difference between the two materials was not large enough to allow the finer material to fill into the voids of the coarser material. As such, the LSF adopted in the present study is not effective to improve the packing density.

Figure 5 shows the wet packing densities and voids ratio of powder paste produced from the OPC (batch 2) blended with different amounts of SFC ( 0 to $30 \%$ by mass of the whole cementitious materials). The results confirm the positive effects of SFC on packing density: replacing $10 \%$ of OPC by SFC was already able to increase the packing density by $5.6 \%$ from 0.640 to 0.676 ; while replacing $20 \%$ of OPC by SFC could further improve the packing density by $8.1 \%$ to 0.692 . The desirable effectiveness of SFC in increasing the packing density is explained by the fine size of SFC, which is similar to the case of CSF shown above. It is noteworthy that there exists an optimum SFC content for achieving the maximum packing density of the powder paste. When the

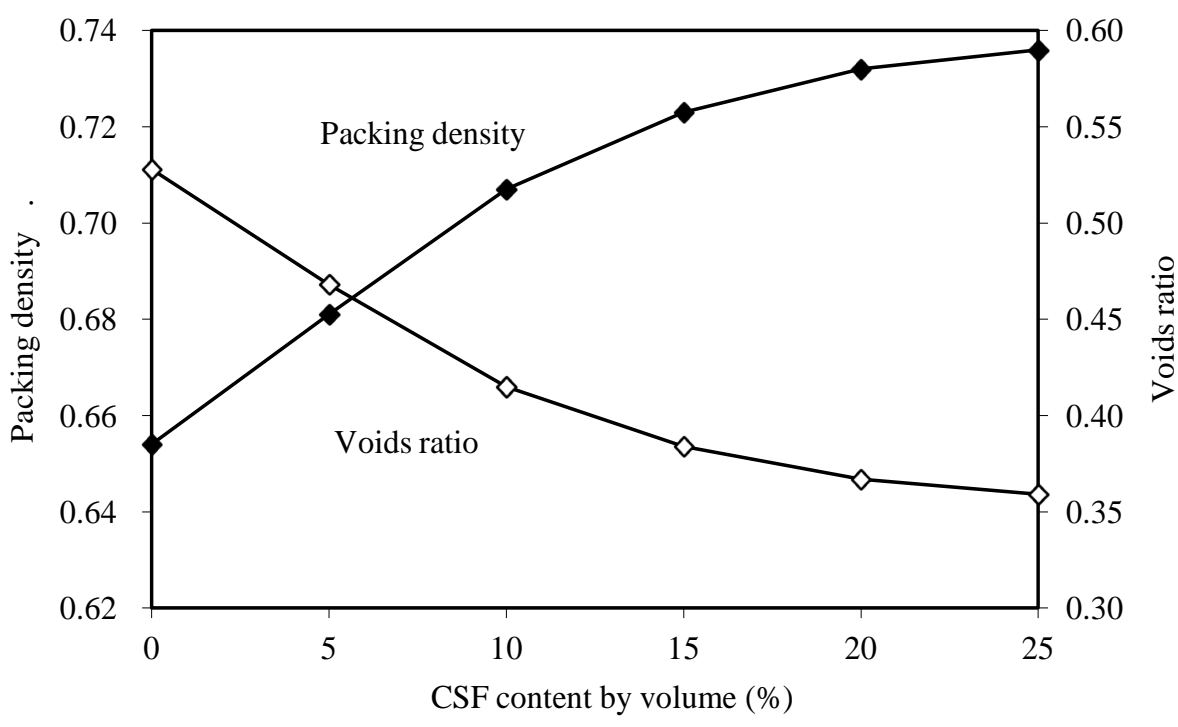

Figure 3. Packing density and voids ratio versus CSF content. 


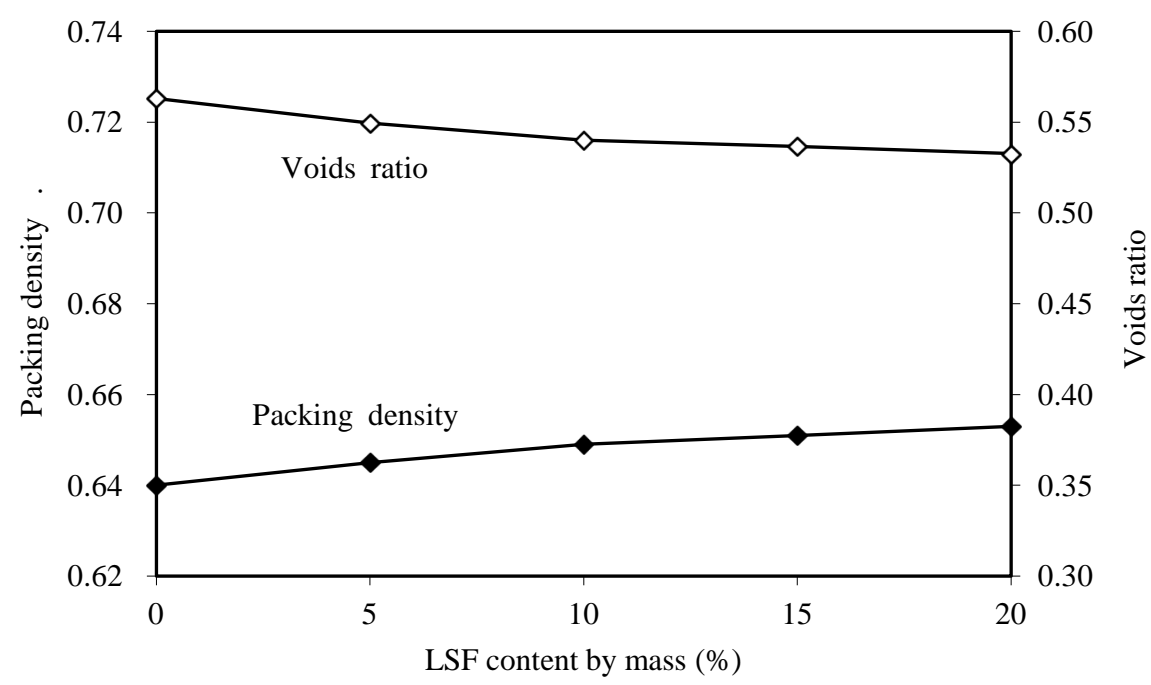

Figure 4. Packing density and voids ratio versus LSF content.

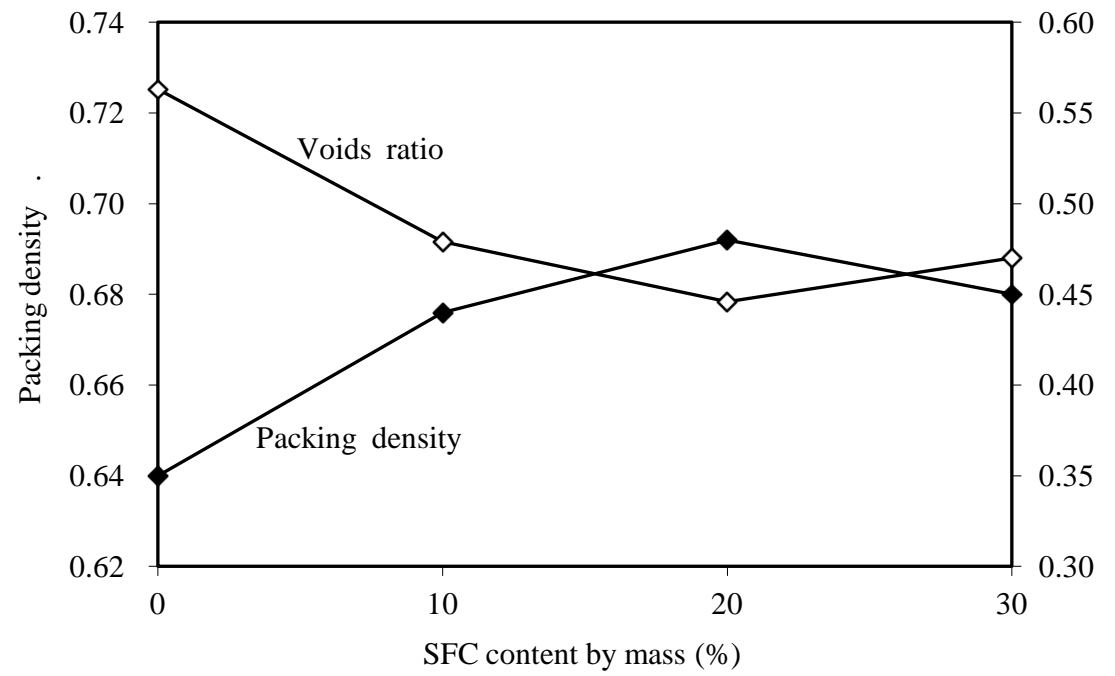

Figure 5. Packing density and voids ratio versus SFC content.

SFC content was increased to $30 \%$, the packing density dropped to 0.680 . This indicates that the packing density would turn to decrease instead of continuing to increase with further addition of SFC when the SFC content was beyond the optimum value. The existence of an optimum SFC content for achieving the maximum packing density may be observed from Figure 5.

It is believed that the great effects of CSF and SFC on packing density improvement are attributed to their filling effects. As the ultrafine particles of CSF have a size of roughly 1/15 of the SFC, it can be expected that the CSF particles could be able to fill the voids between the OPC-SFC grains system and thus further improve the packing density of the powder through OPC-SFC-CSF triple-blending. To study the effects of adding SFC and CSF together, the packing densities of the triple-blended powder mixes containing different amounts of SFC and CSF were measured. As it is the solid volume rather than the mass that matters in particle packing, both the SFC and CSF content were calculated on volumetric basis. The SFC and CSF contents varied from 0 to $20 \%$ in increments of $10 \%$ and from $0 \%$ to $10 \%$ in increments of $5 \%$, respectively, of the whole cementitious materials by volume.

The packing density and voids ratio results of the 9 mixes of OPC(batch 3)-SFC-CSF triple-blended powder at different SFC and CSF replacement contents are plotted in Figure 6. From the experimental results, replacing OPC by $5 \%$ CSF would increase the packing density by $5.2 \%$ from 0.630 to 0.663 , by $6.0 \%$ from 0.646 to 0.685 


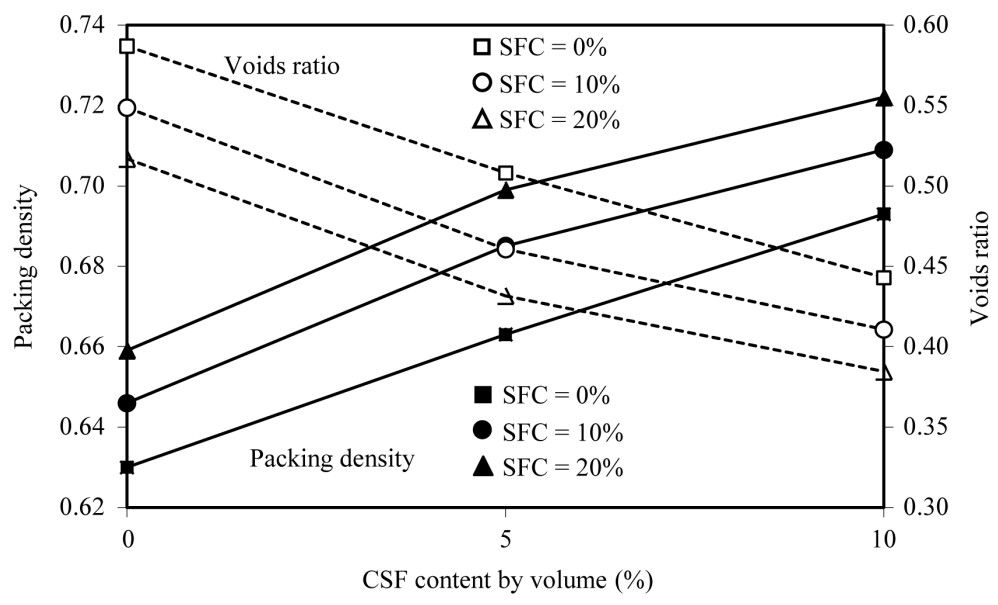

Figure 6. Packing density and voids ratio at different SFC and CSF contents.

and by $6.1 \%$ from 0.659 to 0.699 at 0,10 and $20 \%$ SFC replacement, respectively; while replacing OPC by $10 \%$ CSF would increase the packing density by $10.0 \%$ to 0.693 , by $9.8 \%$ to 0.709 and by $9.6 \%$ to 0.722 at 0,10 and $20 \%$ SFC replacement, respectively. It demonstrates that CSF would benefit the packing density of the cementitious powder with and without SFC. Moreover, as shown in Figure 6, the curves of packing density versus CSF content at different SFC contents are generally parallel, indicating that the rate of increase in the packing density follow the similar trend which is not influenced by the SFC content. Conversely, it could also be observed that the SFC would benefit the packing density at different CSF contents. Thus, compared with adding CSF or SFC alone, triple-blending would be a better way to improve the packing density.

\section{Discussion}

The results presented in the foregoing have proven that the addition of LSF, SFC and CSF would yield different effectiveness in improving the packing density of the powder paste. The addition of LSF could only marginally increase the packing density, while the effects of SFC and CSF are more significant. It is inferred that such difference in effectiveness is attributed to the differences in particle sizes. Since the filling effect of a powder lies in that the particles with smaller size could fill the voids between the particles with larger size, to make the filling effect significant, the filler should be significantly finer than the OPC particles. Because the particle size of LSF is just slightly finer than OPC, it is not able to readily fill into the voids between the OPC grains and consequently the improvement in packing density is limited. On the contrary, as the SFC and CSF have a particle size much finer than OPC, they can effectively fill into the voids between the OPC grains and hence significantly improve the packing density. Referring to the particle size of SFC, it can be put forward that the filler should be at least as fine as $1 / 4$ of the OPC to effectively improve the packing density. Results also show that blending powders with different sizes would be more beneficial to the packing density than using a single size powder only. Similarly, this can be explained by the effectiveness of filling effect. Compared to filling the voids between the larger particles with one single size particles, the filling effect would be better if particles with two or more sizes are used: the medium size particles fill into the voids between the larger size particles whereas the smaller size particles fill into the voids between the medium size particles and this successive fillings continue. Therefore, two or more fillers with different sizes are recommended to be used for improving the packing density of the powder paste.

It is noteworthy that a small increase in packing density is able to bring in significant decrease in the voids ratio. The effects on the voids ratio can be calculated according to Equation (2) and, for easy reference, plotted together with the packing density in Figure 3 to Figure 6. The addition of LSF, SFC and CSF could reduce the voids ratio from 0.563 to $0.533,0.563$ to 0.446 and 0.528 to 0.359 , respectively. Besides, the addition $20 \%$ SFC and $10 \%$ CSF together could reduce the voids ratio from 0.587 to 0.384 . It can be seen that the $2.0 \%, 8.1 \%, 12.5 \%$ and $14.6 \%$ increases in the packing density due to addition of LSF, SFC, CSF and joint addition of SFC and CSF result in 5.3\%, 20.8\%, 32.0\% and 34.6\% decreases in the voids ratio, respectively. These reductions of voids ratio can greatly enhance the performance of concrete through the following two strategies: 1) Increasing the 
flowability by allowing more excess water available for lubrication at the same W/P ratio; and 2) Increasing the strength by allowing the adoption of a lower W/P ratio without compromising the flowability.

\section{Conclusions}

The packing density improvement of cement paste through the addition of limestone fines (LSF), superfine cement (SFC), and condensed silica fume (CSF) has been investigated by using the wet packing test method. Experimental results have indicated that the blending with LSF, SFC and CSF could improve the packing density by $2.0 \%, 8.1 \%$ and $12.5 \%$, respectively. It can be concluded that the use of fine powders with a higher fineness would better improve the packing density but the size should be at least as fine as $1 / 4$ of the OPC in order to effectively improve the packing density. Besides, triple-blending with SFC and CSF has been studied. From the experimental results, CSF would benefit the packing density of the powder paste at different SFC contents, and the rate of increase in the packing density would follow a common trend which is not influenced by the SFC content. Thus, to increase the packing density, the addition of fine powders with different sizes is recommended.

The experimental results have also demonstrated that a small increase in packing density can significantly decrease the voids ratio. Such reduction in voids ratio could result in more excess water (water in excess of that needed to fill the voids) at the same W/P ratio to increase the flowability of concrete. Alternatively, the reduction in voids ratio could allow the W/P ratio to be reduced to improve the strength and durability of the concrete without impairing the flowability. Therefore, the fine fillers are able to play important roles in improving the packing density of powder paste for production of high-performance concrete.

\section{Acknowledgements}

The work described in this paper was fully supported by the grant PhD Start-up Fund of Natural Science Foundation of Guangdong Province, China (Project No. 2014A030310273).

\section{References}

[1] Aïtcin, P.-C. (2016) Ultra High Strength Concrete. Science and Technology of Concrete Admixtures, accepted and abstract available online.

[2] Bharatkumar, B.H., Narayanan, R., Raghuprasad, B.K. and Ramachandramurthy, D.S. (2001) Mix Proportioning of High Performance Concrete. Cement and Concrete Composites, 23, 71-80. http://dx.doi.org/10.1016/S0958-9465(00)00071-8

[3] Aïtcin, P.-C. (2000) Cements of Yesterday and Today: Concrete of Tomorrow. Cement and Concrete Research, 30, 1349-1359. http://dx.doi.org/10.1016/S0008-8846(00)00365-3

[4] Neville, A.M. (2011) Properties of Concrete. 5th Edition, Longman, England.

[5] Kwan, A.K.H. and Wong, H.H.C. (2008) Packing Density of Cementitious Materials: Part 2-Packing and Flow of OPC + PFA + CSF. Materials and Structures, 41, 773-784. http://dx.doi.org/10.1617/s11527-007-9281-6

[6] Powers, T.C. (1968) The Properties of Fresh Concrete. John Wiley \& Sons, New York, 533-652.

[7] Huang, C.Y. and Feldman, R.F. (1985) Hydration Reactions in Portland Cement-Silica Fume Blends. Cement and Concrete Research, 15, 585-592. http://dx.doi.org/10.1016/0008-8846(85)90056-0

[8] Feldman, R.F. and Huang, C.Y. (1985) Properties of Portland Cement-Silica Fume Pastes I. Porosity and Surface Properties. Cement and Concrete Research, 15, 765-774. http://dx.doi.org/10.1016/0008-8846(85)90141-3

[9] De Larrard, F. and Sedran, T. (1994) Optimization of Ultra-High-Performance Concrete by the Use of a Packing Model. Cement and Concrete Research, 24, 997-1009. http://dx.doi.org/10.1016/0008-8846(94)90022-1

[10] Sedran, T., De Larrard, F., Hourst, F. and Contamines, C. (1996) Mix Design of Self-Compacting Concrete. Proceedings of the International RILEM Conference on Production Methods and Workability of Concrete, Paisley, 439-450.

[11] Lange, F., Mörtel, H. and Rudert, V. (1997) Dense Packing of Cement Pastes and Resulting Consequences on Mortar Properties. Cement and Concrete Research, 27, 1481-1488. http://dx.doi.org/10.1016/S0008-8846(97)00189-0

[12] Jones, M.R., Zheng, L. and Newlands, M.D. (2003) Estimation of the Filler Content Required to Minimise Voids Ratio in Concrete. Magazine of Concrete Research, 55, 193-202. http://dx.doi.org/10.1680/macr.2003.55.2.193

[13] Nehdi, M., Mindess, S. and Aïtcin, P.-C. (1998) Rheology of High-Performance Concrete: Effect of Ultrafine Particles. Cement and Concrete Research, 28, 687-697. http://dx.doi.org/10.1016/S0008-8846(98)00022-2

[14] Park, C.K., Noh, M.H. and Park, T.H. (2005) Rheological Properties of Cementitious Materials Containing Mineral 
Admixtures. Cement and Concrete Research, 35, 842-849. http://dx.doi.org/10.1016/S0008-8846(98)00022-2

[15] ACI Committee 234 (2006) Guide for the Use of Silica Fume in Concrete. American Concrete Institute, Detroit.

[16] Claisse, P.A., Lorimer, P. and Al Omari, M. (2001) Workability of Cement Pastes. ACI Materials Journal, 98, 476482.

[17] Ji, Y.J. and Cahyadi, J.H. (2003) Effects of Densified Silica Fume on Microstructure and Compressive Strength of Blended Cement Pastes. Cement and Concrete Research, 33, 1543-1548. http://dx.doi.org/10.1016/S0008-8846(03)00100-5

[18] Austin, S.A. and Robins, P.J. (1994) The Influence of Superplasticizer on Mixture Proportioning and the Strength and Durability of Silica Fume Concrete. Proceedings of 4th CANMET/ACI International Conference on Superplasticizers and Other Chemical Admixtures in Concrete, ACI Special Publications SP-148, American Concrete Institute, 259-280.

[19] Khatri, R.P., Sirivivatnanon, V. and Gross, W. (1995) Effect of Different Supplementary Cementitious Materials on Mechanical Properties of High Performance Concrete. Cement and Concrete Research, 25, 209-220. http://dx.doi.org/10.1016/0008-8846(94)00128-L

[20] Jayasree, C. and Gettu, R. (2008) Experimental Study of the Flow Behaviour of Superplasticized Cement Paste. Materials and Structures, 41, 1581-1593. http://dx.doi.org/10.1617/s11527-008-9350-5

[21] Aydin, S., Hilmi Aytaç, A. and Ramyar, K. (2009) Effects of Fineness of Cement on Polynaphthalene Sulfonate Based Superplasticizer-Cement Interaction. Construction and Building Materials, 23, 2402-2408. http://dx.doi.org/10.1016/j.conbuildmat.2008.10.004

[22] Kwan, A.K.H. and Ng, I.Y.T. (2009) Optimum Superplasticizer Dosage and Aggregate Proportions for SCC. Magazine of Concrete Research, 61, 281-292. http://dx.doi.org/10.1680/macr.2008.00010

[23] Wong, H.H.C. and Kwan, A.K.H. (2008) Packing Density of Cementitious Materials: Part 1-Measurement Using a Wet Packing Method. Materials and Structures, 41, 689-701. http://dx.doi.org/10.1617/s11527-007-9274-5

\section{Submit or recommend next manuscript to SCIRP and we will provide best service for you:}

Accepting pre-submission inquiries through Email, Facebook, LinkedIn, Twitter, etc. A wide selection of journals (inclusive of 9 subjects, more than 200 journals)

Providing 24-hour high-quality service

User-friendly online submission system

Fair and swift peer-review system

Efficient typesetting and proofreading procedure

Display of the result of downloads and visits, as well as the number of cited articles

Maximum dissemination of your research work

Submit your manuscript at: http://papersubmission.scirp.org/ 